\title{
The safety and efficacy of percutaneous intraductal radiofrequency ablation in unresectable malignant biliary obstruction: A single-institution experience
}

Wei Cui ${ }^{\dagger}$, Wenzhe Fan ${ }^{\dagger}$, Mingjian Lu, Yingqiang Zhang, Wang Yao, Jiaping Li ${ }^{*}$ and Yu Wang ${ }^{*}$

\begin{abstract}
Background: Patients with unresectable malignant biliary obstruction have limited life expectancy because of limited stent patency and tumor progression. The aim of our study was to retrospectively evaluate the safety and efficacy of combining intraductal RFA with biliary metal stent placement for patients with malignant biliary obstruction.

Methods: Patients who received percutaneous intraductal RFA and biliary stent placement for malignant biliary obstruction between 2013 and 2015 were identified. Outcomes were stent patency, technique and clinical success rate, overall survival (OS) and complication rates. Kaplan-Meier and Cox regression analyses were used to examine the association of various factors with stent patency and OS. Complications and laboratory abnormalities were recorded.
\end{abstract}

Results: Fifty patients were treated with percutaneous RFA and stent placement. The rates of technical success and clinical success were 98\% and 92\%, respectively. The median stent patency was 7.0 (95\% confidence interval [CI]: 5. 3 , 8.7) months and OS was 5.0 ( $95 \%$ Cl: 4.0,6.0) months. On univariable analysis, previously cholangitis was an independent poor prognosis factor for recurrent biliary obstruction. OS was improved in patients who received more than one intervention compared to those who received only one intervention (log-rank $P=0.007$ ), and in those treated without versus those treated with sequential chemotherapy (log-rank $P=0.017$ ). On multivariable analysis, the occurrence of more than one intervention $(P=0.019)$ had independent prognostic significance for OS.

Conclusion: Percutaneous RFA and stent placement is a technically safe and feasible therapeutic option for the palliative treatment of malignant biliary obstruction. The long-term efficacy and safety of the procedure is promising, but further study is required via randomized and prospective trials.

Keywords: Radiofrequency catheter ablation, Self expandable metal stent, Bile duct obstruction, Radiology, interventional

\footnotetext{
*Correspondence: jiapingli3s@126.com; fishking66@126.com

${ }^{\dagger}$ Equal contributors

Department of Interventional Oncology, the First Affiliated Hospital, Sun

Yat-sen University, Guangzhou 510080, China
}

(c) The Author(s). 2017 Open Access This article is distributed under the terms of the Creative Commons Attribution 4.0 International License (http://creativecommons.org/licenses/by/4.0/, which permits unrestricted use, distribution, and reproduction in any medium, provided you give appropriate credit to the original author(s) and the source, provide a link to the Creative Commons license, and indicate if changes were made. The Creative Commons Public Domain Dedication waiver (http://creativecommons.org/publicdomain/zero/1.0/) applies to the data made available in this article, unless otherwise stated. 


\section{Background}

Patients with malignant biliary obstruction due to different types of tumors, including pancreatic, bile duct, gallbladder, and hepatocellular carcinomas, frequently have a poor prognosis in terms of quality of life and survival. These cancers are often surgically unresectable at the time of diagnosis, and those that are resected have high recurrence rates [1]. Placement of self-expandable metal stents (SEMS) is the standard of care in the palliative management of patients with malignant biliary strictures if their life expectancy is at least 3 months [2]. However, maintaining patency is a problem, with tumor overgrowth, epithelial hyperplasia, biofilm deposition, and sludge formation limiting the median patency of metal stents to a mere 6 months [3].

Despite attempts to find a potential solution to the problem of SEMS occlusion, including the use of covered stents, different stent designs, and biliary intraluminal irradiation stents, little progress has been made in terms of improving the duration of stent patency [4-7]. Although photodynamic therapy (PDT) has been reported as an alternative capable of increasing the rate of stent patency, it is expensive and time consuming, and is associated with cholangitis and photosensitivity $[8,9]$. Recently, a Percutaneous Endobiliary Radiofrequency catheter (Habib ${ }^{\text {mi }}$ PERF; EMcision Ltd., London, UK) was developed specifically to attempt to solve the problem of stent occlusion. Studies using ex-vivo and in-vivo pig models have clarified the effectiveness of the Habib PERF catheter, with an output power of 7-10 W and an ablation time of 2 min recommended for clinical treatment $[10,11]$. An open-label pilot study involving 22 patients with malignant biliary strictures confirmed the safety and feasibility of this radiofrequency ablation (RFA) technique for clinical use [12]. The technique has shown promising results in the palliative treatment of malignant biliary strictures, preventing stent occlusion [13-18], clearing blocked metal stents [7], prolonging stent patency [19], and improving patient survival [20]. We previously reported our early experience in managing patients with unresectable Bismuth types III and IV hilar cholangiocarcinoma using biliary RFA, and demonstrated that the long-term efficacy and safety is promising [21]. Here, we describe a broader experience in managing 50 patients using biliary RFA in an effort to improve long-term stent patency in unresectable malignant biliary obstruction. We also examined the prognostic factors for stent patency in these patients.

\section{Methods}

We conducted a retrospective study of consecutive patients with malignant biliary obstruction who underwent biliary RFA and stent placement at the First Affiliated Hospital of Sun Yat-sen University between 2013 and
2015. Malignant biliary obstruction was diagnosed in all cases on the basis of the characteristic clinical features (jaundice and/or clay colored stool), laboratory tests (elevated bilirubin levels and alkaline phosphatase levels), and imaging findings. Access to the database and the methods used for data retrieval and analysis were approved by the ethics committee of our hospital, and written informed consent was obtained from each participant in accordance with the Declaration of Helsinki.

\section{Study participants}

The inclusion criteria were (1) age $\geq 20$ years; (2) malignant biliary obstruction confirmed using computed tomography (CT) or abdominal magnetic resonance imaging (MRI), with pathological confirmation whenever possible; (3) clinical jaundice, a serum bilirubin level greater than $5 \mathrm{mg} / \mathrm{dL}$, and/or cholangitis; (4) performance status score $\leq 2$ [22]; (5) unresectability or refusal to be surgically treated. Eligible patients were those with biliary obstruction due to cancer of the pancreas, gallbladder, or bile ducts; primary and secondary liver cancers; or regional lymph node metastases, who were considered unsuitable for surgery because of distant metastases, vascular invasion, or severe disability due to age or associated diseases. Non-resectability was established through the consensus opinion of a multidisciplinary tumor board. Identified patients were screened with the following exclusion criteria: (1) performance status score $\geq 3$; (2) identification of a secondary malignancy; and (3) lost to follow-up or missing data.

\section{Treatment}

The Habib ${ }^{\text {Tx }}$ EndoHPB is an 8-Fr. (2.6 mm), 1.8-m long bipolar RFA catheter with two radiologically marked electrodes at its tip and is inserted over a 0.035 -in. guide wire into the bile duct [21]. This catheter can be used for either an endoscopic retrograde cholangiopancreatography (ERCP) or a percutaneous transhepatic cholangiography (PTC) procedure. Under digital subtraction angiography (DSA) guidance, PTC was performed to localize the site of biliary obstruction and to confirm its length and diameter. A guide wire was then passed through the stenosis via the percutaneous drainage catheter. The Habib EndoHBP probe was advanced over the wire with the tip of the probe placed across the malignant stricture. The probe was attached to a standard high-frequency generator, with $10 \mathrm{~W}$ applied for $90 \mathrm{~s}$ [21]. For patients with long segmental obstruction of the bile duct, RFA was performed section by section. For patients with high-level obstruction and tumors involving the bilateral bile ducts, RFA of the bilateral intrahepatic bile ducts was necessary. Immediately after RFA, uncovered SEMS (Wallstent; Boston Scientific, Boston), mounted on a delivery system, were placed. Generally, 
the SEMS were selected according to the individual radiologist's preference and the manufacturer's protocol [21]. Cholangiography was used to confirm that the bile duct was clear. Follow-up assessment of drainage flow was performed under DSA guidance three to four days after the procedure, and the catheter was removed if the flow remained unobstructed.

\section{Re-intervention}

In the event of recurrence of cholangitis or jaundice, abdominal CT was performed to verify stent patency, and when dilation of the drained bile duct was confirmed, repeat-ablation with or without a stent was attempted. On the other hand, when dilation of the drained bile duct was not confirmed, focal cholangitis of another undrained branch of the bile duct was suspected, and stent placement with RFA was attempted for that branch. If drainage failed, percutaneous transhepatic cholangial drainage was performed.

\section{Assessment and follow-up}

Technical success was defined as passage of the stent across the stricture, with good radiographic positioning, along with flow of contrast and/or bile through the stent [23]. Clinical success was defined as the improvement of symptoms such as jaundice, pruritus, and total bilirubin levels to less than half or less than the normal upper limit within 14 days. Stent patency was defined as the interval between the first stent insertion procedure and the recurrence of the symptoms of restructure without repeat-ablation or stent insertion. If there was no evidence of obstruction while the patient was alive, the patency period was considered to be equal to the survival period, but was censored. Stent patency was confirmed by the absence of jaundice, normal levels of direct bilirubin, and the absence of bile duct expansion on US, CT or MR imaging during follow-up [19]. Overall survival (OS) was calculated from the date of the first procedure until the date of death.

The incidence of complications associated with the procedures was investigated. The major adverse events that were assessed included bleeding, infection, pancreatitis, pain, recurrent biliary obstruction, and bile perforation. Mild bleeding was defined as no requirement for transfusion within $48 \mathrm{~h}$. Moderate bleeding was defined as a need for a blood transfusion of more than 2 units or a haemostatic procedure, including both pharmaceutical and surgical intervention, after a drainage procedure [24]. Acute pancreatitis was diagnosed in the presence of elevated pancreatic enzyme levels $\geq 3$ times the upper limit of the normal range within $24 \mathrm{~h}$ of the procedure and with symptoms of pancreatitis. Post-procedure pain was defined as follows: (1) mild pain, which was noted as any pain requiring short-term treatment with oral analgesics, (2) moderate or severe pain, which included any symptoms necessitating hospital admission or the use of intravenous analgesics [25]. The definitions of causes of recurrent biliary obstruction, such as tumor ingrowth or overgrowth, and stent migration, were based on the 2014 Tokyo criteria for transpapillary biliary stenting [26].

Outcomes were stent patency, OS, technical success, clinical success, and complications. After adequate palliation of the biliary obstruction, patients were discharged, with follow-up arranged through the outpatient clinic at two-week to three-month intervals. Patients' continuing medical history and the results of physical examination and laboratory studies were included in the medical record. Patients who died were excluded at the date of their last follow-up. Follow-up continued from the first operation to the death of the patient or the end of the study.

\section{Statistical analysis}

Descriptive statistics were calculated, using the mean \pm standard deviation (SD) or median and range, as appropriate for the data type. Stent patency and OS were evaluated using Kaplan-Meier curves, with betweengroup differences compared using the log-rank test. Variables with potential prognostic significance for stent patency and OS were assessed through univariable analysis. Significant variables on univariable analysis were included in a multivariable Cox regression model. All analyses were performed using SPSS statistics software (SPSS, Version 16.0 for Windows; Chicago, IL). All $P$ values were two sides, with a level of 0.05 considered to be significant.

\section{Results}

\section{Patient characteristics}

In the final analysis, 50 patients who received intraductal RFA and stent placement for unresectable malignant biliary obstruction between 2013 and 2015 were included. The baseline characteristics are shown in Table 1 . Among the patients, 38\% $(n=19)$ had undergone prior primary tumor resection, 22 (44\%) had cholangitis, and 29 (58\%) had distant metastases at baseline. The mean baseline total and direct bilirubin (TB, DB) levels were $198.4 \mu \mathrm{mol} / \mathrm{L}$ (median, $168 \mu \mathrm{mol} / \mathrm{L} ; \mathrm{SD}, 167.2 \mu \mathrm{mol} / \mathrm{L}$ ) and $108.1 \mu \mathrm{mol} / \mathrm{L}$ (median, $95.1 \mu \mathrm{mol} / \mathrm{L} ; \mathrm{SD}, 83.4 \mu \mathrm{mol} /$ $\mathrm{L})$, respectively. The mean baseline gamma-glutamyl transpeptidase level (GGT) was $405.68 \mathrm{U} / \mathrm{L}$ (median, $311 \mathrm{U} / \mathrm{L} ; \mathrm{SD}, 278.2 \mathrm{U} / \mathrm{L})$.

\section{Treatment details}

All patients received percutaneous intra-ductal RFA and stent placement, and $14 \%(n=7)$ received subsequent platinum-based chemotherapy. Unilateral stent placement was performed in 39 (78\%) patients, with $11(22 \%)$ 
Table 1 Patient Characteristics

\begin{tabular}{|c|c|c|}
\hline Category & Subcategory & Number (\%) \\
\hline Total & & 50 \\
\hline Median age(range), yr. & & $61.8(41-85)$ \\
\hline \multicolumn{3}{|l|}{ Sex } \\
\hline & Male & $36(72)$ \\
\hline & Female & $14(28)$ \\
\hline \multicolumn{3}{|l|}{ Type of tumor } \\
\hline & Pancreatic carcinoma & $10(20)$ \\
\hline & Gallbladder carcinoma & $4(8)$ \\
\hline & Cholangiocarcinoma & $25(50)$ \\
\hline & Hepatocelluar carcinoma & $6(12)$ \\
\hline & Lymph node metastases & $5(10)$ \\
\hline \multicolumn{3}{|l|}{ Level of biliary obstruction ${ }^{*}$} \\
\hline & Common bile or hepatic duct (type I) & $11(22)$ \\
\hline & Type ॥ & $8(16)$ \\
\hline & Type III A & 10(20) \\
\hline & Type III B & $4(8)$ \\
\hline & Intrahepatic (type IV) & $17(34)$ \\
\hline \multicolumn{3}{|l|}{ Performance status score } \\
\hline & 0 & $10(20)$ \\
\hline & 1 & $20(40)$ \\
\hline & 2 & $18(36)$ \\
\hline Previously cholangitis & & $22(44)$ \\
\hline Distant Metastasis & & $29(58)$ \\
\hline No. of interventions, mean (range) & & $1.2(1-3)$ \\
\hline Subsequent chemotherapy & & $7(14)$ \\
\hline
\end{tabular}

Note. - Unless otherwise indicated, data are number of patients and data in parentheses are percentages

*According to the Bismuth classification of perihilar cholangiocarcinoma

patients requiring bilateral stents at the initial procedure. Forty-two (84\%) patients underwent one ablation and stent placement session, while six (12\%) underwent two sessions (four of them without new stent placement), and two (4\%) underwent three ablations without stent placement sessions due to recurrent biliary obstruction.

\section{Outcomes}

Complications related to the procedures are shown in Table 2. No severe complications, such as bile duct perforation, bile leak, or acute pancreatitis, were identified post-procedure. Four patients required blood transfusion for post-procedure bleeding. However, two patients died within 30 days after the RFA procedure, both due to cholangitis and septic shock. Furthermore, one patient with a history of coronary heart disease, percutaneous coronary intervention, atrial fibrillation, hypertension, and hyperthyroidism, developed an acute state of chronic heart failure caused by atrial fibrillation and rapid ventricular rate. Conservative treatment was successful for this patient. Of note is the incidence rate of new cholangitis, with an overall rate of $32 \%$ (16 of 50 patients). Patients presented symptoms of bacterial

Table 2 Outcome of procedures in two groups

\begin{tabular}{ll}
\hline Outcome & Number (\%) \\
Mild bleeding & $23(46)$ \\
\hline Moderate bleeding & $4(8)$ \\
Mild pain & $18(36)$ \\
Moderate or severe pain & $4(8)$ \\
Bile infection & $16(32)$ \\
Acute pancreatitis & 0 \\
Recurrent obstruction & \\
Tumor ingrowth & $6(12)$ \\
Tumor overgrowth & $8(16)$ \\
Stent migration & $1(2)$ \\
New stricture & $3(6)$ \\
Unkown & $1(2)$ \\
\hline
\end{tabular}


cholangitis, with antibiotic treatment being successful to resolve fever and normalize white blood cell counts.

The rates of technical and clinical success were 98\% $(n=49)$ and $92 \%(n=46)$. Liver function tests were performed before, immediately after (2-4 days after the procedure), and 1 month after the procedure in all patients except for the two who died within 30 days (Fig. 1 ). Between the time before and the time immediately after ablation, the following parameters improved significantly: mean TB $(\mathrm{P}<0.001)$, DB $(\mathrm{P}<0.001)$, alanine aminotransferase (ALT) $(\mathrm{P}<0.001)$, and aspartate aminotransferase (AST) $(\mathrm{P}<0.001)$. Short-term follow-up showed the preservation of increased liver function for 1 month.

The median follow-up was 6 months, and 10 (20\%) patients were still alive at the time of data analysis. Five patients died of recurrent cholangitis and sepsis shock, one of heart disease, two of gastrointestinal haemorrhage, and 32 of tumor progression. The median stent patency was 7.0 (range 1.5-10, 95\% confidence interval [CI]: 5.3, 8.7) months and median survival (from the first procedure until death or last follow-up) was 5.0 (range 0.2519.2, 95\% CI: 4.0, 6.0) months (Figs. 2 and 3). Univariable and multivariable Cox regression analyses for factors associated with stent patency and OS are presented in Table 3 and Table 4. In univariable analysis, there was no significant difference in the stent patency when patients were stratified by age, sex, performance status score, level of biliary obstruction, distant metastasis, or sequential chemotherapy $(P=0.024)$. Previously cholangitis was an independent poor prognosis factor for recurrent biliary obstruction (Table 3). However, OS was improved in patients who received more than one intervention compared to those who received only one

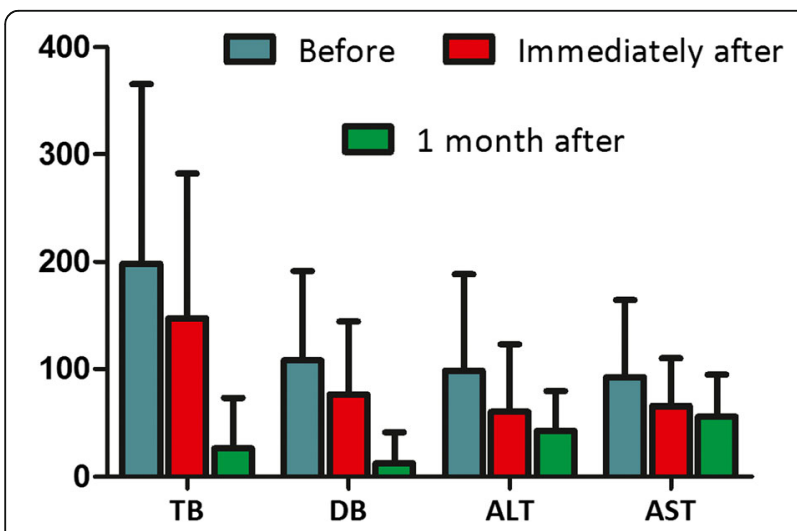

Fig. 1 Liver function before and after RFA and stent placement. Bar chart shows the results of liver function tests before and after RFA and stent placement. Total bilirubin (TB), direct bilirubin (DB), alanine aminotransferase (ALT), and aspartate aminotransferase (AST) were obtained before, immediately after, and 1 month after RFA and stent placement. Data are means \pm standard errors of the mean

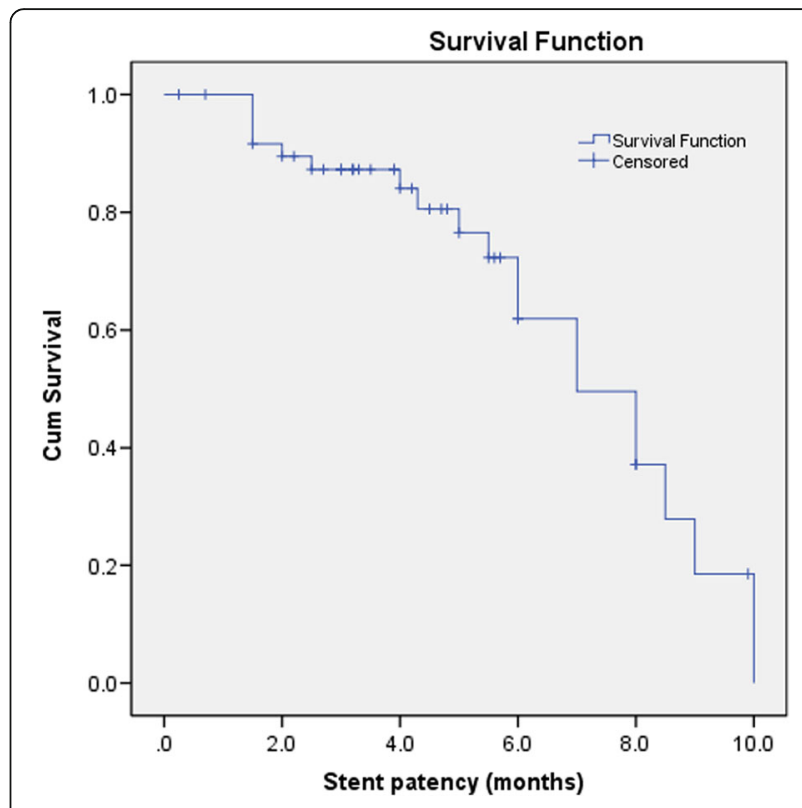

Fig. 2 Kaplan-Meier curve of stent patency. The calculation started on the day of the first RFA procedure and extended to the time of proven stent occlusion, stent migration, or patient death

intervention $(P=0.007)$, and in those treated without versus those treated with sequential chemotherapy (logrank $P=0.017$ ). On multivariable analysis, only the occurrence of more than one intervention remained independently significant (Table 4). None of the tested cutoff points for TB, DB, ALT, AST, and GGT were

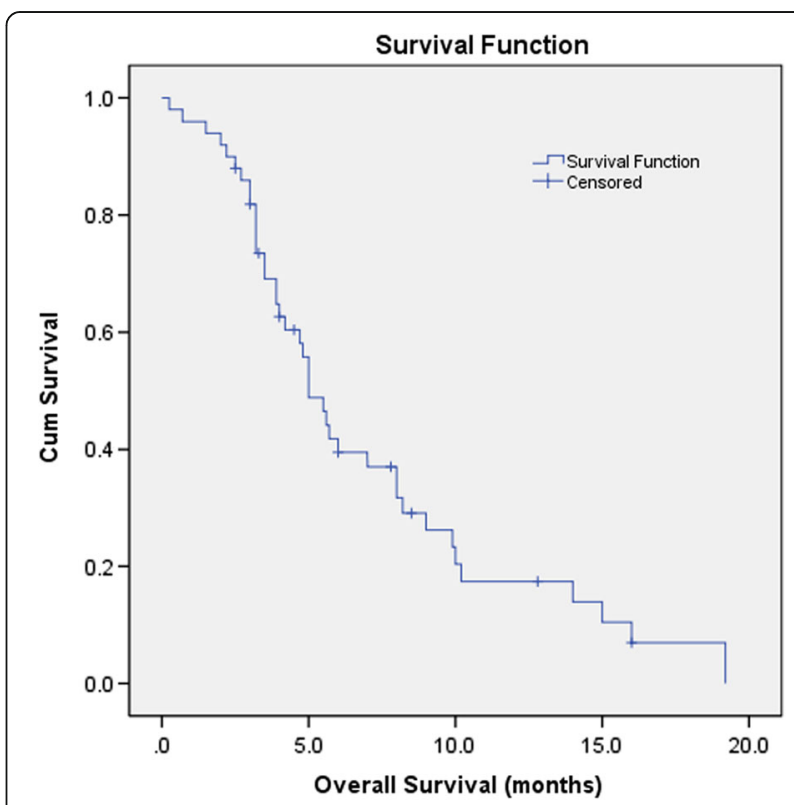

Fig. 3 Kaplan-Meier survival curve of overall survival. The calculation started on the date of the first procedure until the date of death or last follow-up 
Table 3 Risk of Recurrence of Biliary Obstruction in Patients with Unresectable Malignant Biliary Obstruction after Therapy

\begin{tabular}{|c|c|c|c|c|c|}
\hline & & Univariate Analysis & & Multivariate Analysis & \\
\hline Variable* & No. of cases & $\mathrm{HR}(95 \% \mathrm{Cl})$ & $\mathrm{P}+$ & $\mathrm{HR}(95 \% \mathrm{Cl})$ & $\mathrm{P}^{\dagger}$ \\
\hline Age $(\geq 62$ y vs $<62$ y) & $25 / 25$ & $2.348(0.840,6.566)$ & 0.104 & & \\
\hline Sex(male vs female) & $36 / 14$ & $1.243(0.404,3.827)$ & 0.705 & & \\
\hline Tumor diagnosis (Cholangiocarcinoma vs other neoplasms) & $25 / 25$ & $1.770(0.679,4.612)$ & 0.243 & & \\
\hline Type of obstruction(proximal vs distal) & $19 / 31$ & $0.899(0.324,2.494)$ & 0.838 & & \\
\hline Performance status score (2 vs $\leq 1$ ) & $32 / 18$ & $1.706(0.890,3.270)$ & 0.108 & & \\
\hline Previously cholangeitis (no vs yes) & $28 / 22$ & $3.347(1.176,9.525)$ & 0.024 & $3.347(1.176,9.525)$ & 0.024 \\
\hline Distant Metastasis(yes vs no) & $29 / 21$ & $1.292(0.490,3.403)$ & 0.605 & & \\
\hline Chemotherapy (no vs yes) & $43 / 7$ & $0.840(0.277,2.547)$ & 0.759 & & \\
\hline $\mathrm{TB}(\geq 168.0 \mu \mathrm{mol} / \mathrm{L}$ vs $<168.0 \mu \mathrm{mol} / \mathrm{L})$ & $25 / 25$ & $0.488(0.184,1.294)$ & 0.149 & & \\
\hline $\mathrm{DB}(\geq 95.1 \mu \mathrm{mol} / \mathrm{L}$ vs $<95.1 \mu \mathrm{mol} / \mathrm{L})$ & $25 / 25$ & $0.485(0.183,1.287)$ & 0.146 & & \\
\hline $\operatorname{ALT}(\geq 71 \mathrm{U} / \mathrm{L}$ vs $<71 \mathrm{U} / \mathrm{L})$ & $25 / 25$ & $1.352(0.491,3.728)$ & 0.560 & & \\
\hline AST ( $\geq 72.5$ U/L vs $<72.5 \mathrm{U} / \mathrm{L})$ & $25 / 25$ & $0.887(0.348,2.261)$ & 0.801 & & \\
\hline GGT( $\geq 311 \mathrm{U} / \mathrm{L}$ Vs $<311 \mathrm{U} / \mathrm{L})$ & $25 / 25$ & $0.613(0.228,1.652)$ & 0.334 & & \\
\hline
\end{tabular}

Note- $T B=$ total bilirubin, $D B=$ direct bilirubin, $A L T=$ alanine aminotransferase, $A S T=$ aspartate aminotransferase, $G-G T=$ gamma-glutamyl transpeptidase *For continuous variables, cutoff level chosen for continuous variables was their median value

$+P$ values were determined with Cox proportional hazards regression models. $P<0.05$ indicated a significant difference

statistically significant in univariable and multivariable analyses (Table 3 and Table 4).

\section{Discussion}

We report the efficacy and complications encountered at our institution for 50 patients treated with percutaneous intra-ductal RFA for unresectable malignant biliary obstruction. Compared to the 3 to 6 -month patency of metal stents alone, the median stent patency of
7.0 months observed in this study is promising and highlights the urgent need for the use of the procedure in select patients [3]. Until now, PDT was the only evidencebased treatment other than stenting that improved the quality of life and survival of such patients [27]. Recently, Daniel [25] reported that RFA and PDT are associated with comparable survival in the treatment of unresectable cholangiocarcinoma. Therefore, these studies all suggest a possible survival benefit in the use of

Table 4 Risk of Death in Patients with Unresectable Malignant Biliary Obstruction after Therapy

\begin{tabular}{|c|c|c|c|c|c|}
\hline & & Univariate Analysis & & Multivariate Analysis & \\
\hline Variable* & No. of cases & $\mathrm{HR}(95 \% \mathrm{Cl})$ & $\mathrm{P}+$ & $\mathrm{HR}(95 \% \mathrm{Cl})$ & $P^{\dagger}$ \\
\hline Age $(\geq 62$ y vs $<62$ y) & $25 / 25$ & $0.776(0.379,1.589)$ & 0.488 & & \\
\hline Sex(male vs female) & $36 / 14$ & $0.803(0.475,1.359)$ & 0.414 & & \\
\hline Tumor diagnosis (Cholangiocarcinoma vs other neoplasms) & $25 / 25$ & $0.825(0.439,1.552)$ & 0.552 & & \\
\hline Type of obstruction(proximal vs distal) & $19 / 31$ & $0.932(0.490,1.775)$ & 0.825 & & \\
\hline Performance status score (2 vs $\leq 1$ ) & $32 / 18$ & $1.706(0.890,3.270)$ & 0.108 & & \\
\hline No. of interventions ( 1 vs $\geq 2$ ) & $42 / 8$ & $0.187(0.055,0.630)$ & 0.007 & $0.295(0.106,0.818)$ & 0.019 \\
\hline Previously cholangeitis (no vs yes) & $28 / 22$ & $0.794(0.405,1.555)$ & 0.500 & & \\
\hline Distant Metastasis(yes vs no) & $29 / 21$ & $0.897(0.474,1.698)$ & 0.739 & & \\
\hline Chemotherapy (no vs yes) & $43 / 7$ & $0.273(0.094,0.792)$ & 0.017 & $2.0 .465(0.159,1.365)$ & 0.164 \\
\hline $\mathrm{TB}(\geq 168.0 \mu \mathrm{mol} / \mathrm{L}$ vs $<168.0 \mu \mathrm{mol} / \mathrm{L})$ & $25 / 25$ & $1.038(0.544,1.978)$ & 0.911 & & \\
\hline $\mathrm{DB}(\geq 95.1 \mu \mathrm{mol} / \mathrm{L}$ vs $<95.1 \mu \mathrm{mol} / \mathrm{L})$ & $25 / 25$ & $0.901(0.475,1.706)$ & 0.748 & & \\
\hline $\operatorname{ALT}(\geq 71 \mathrm{U} / \mathrm{L}$ vs $<71 \mathrm{U} / \mathrm{L})$ & $25 / 25$ & $1.495(0.791,2.825)$ & 0.216 & & \\
\hline AST ( $\geq 72.5$ U/L vs $<72.5 \mathrm{U} / \mathrm{L})$ & $25 / 25$ & $1.087(0.575,2.056)$ & 0.798 & & \\
\hline GGT( $\geq 311 \mathrm{U} / \mathrm{L}$ vs $<311 \mathrm{U} / \mathrm{L})$ & $25 / 25$ & $1.100(0.584,2.072)$ & 0.767 & & \\
\hline
\end{tabular}

Note- $T B=$ total bilirubin, $D B=$ direct bilirubin, $A L T=$ alanine aminotransferase, $A S T=$ aspartate aminotransferase, $G$-GT = gamma-glutamyl transpeptidase *For continuous variables, cutoff level chosen for continuous variables was their median value

$+P$ values were determined with Cox proportional hazards regression models. $P<0.05$ indicated a significant difference 
RFA. However, the results must be interpreted cautiously, because of the retrospective design with many sources of bias. The improvements of SEMS patency, cost-effectiveness, and survival advantages should be confirmed by further randomized controlled trials, if any. The main limitations of our study included its retrospective nature, the fact that it was a single-center experience with heterogeneous etiologies, and lack of a control group.

The potential therapeutic effect of combined RFA and stent placement has only been evaluated in a few studies to date, with mixed findings reported $[9,19,20,28,29]$. The 7 -month stent patency reported here (95\% CI: 5.3 , 8.7 ) is in agreement with the results of the study reported by Werner et al. (median metal stent patency: 7.3 months) [29] but is higher than that reported by Tian-Tian et al. (stent patency: 5.0 months) [28]. Our study and that reported by Werner et al. had higher rates of cholangiocarcinoma ( $50 \%$ and $88 \%$, respectively) and sequential chemotherapy $(14 \%$ and $41 \%$, respectively) compared with the rates in the trial reported by Tian-Tian et al. ( $48 \%$ and $4 \%$, respectively), which is a possible explanation for this discrepancy. Therapeutically, intraluminal RFA and stent placement offers several benefits. Foremost, the local thermal effect can destroy the malignant biliary stricture, resulting in a local coagulation necrosis that has the potential to delay tumor growth and, therefore, prolong the duration of stent patency [16]. This local effect on tumor tissue was confirmed by Monga et al. [13], who reported the disappearance of tumor blood vessels and enlargement of the lumen following RFA. Moreover, RFA can be used to clear the occlusion of a previously deployed metal stent, and restore the biliary flow without the need to insert a new stent inside the obstructed stent [7]. As the use of RFA is not restricted to a single session, repeated treatments and multiple sessions can be performed to increase tumor destruction and improve the stent patency, which is an independent prognosis factor for patient survival (Table 4). Successful biliary drainage and long-term stent patency are important to alleviate clinical symptoms, confer some benefits to improve liver function (Fig. 1), improve performance status scores, and provide an opportunity for subsequent treatment of the primary tumor. However, the median OS (5.0 months) is shorter than the stent patency (7.0 months). This is likely because many patients still had patent stents at the time of the last follow-up or death. Furthermore, due to local tumor progression, many patients in our study died of disease progression but not recurrent stent obstruction, and only a few patients received repeat-ablation. In the Cox analysis, OS was improved in patients who received more than one intervention compared to those who received only one intervention $(\log$-rank $P=0.007)$. The RFA heat penetration depth is limited and the coagulation zone is too small in patients who have tumors that involve the bile duct but do not originate from the bile duct epithelium (such as pancreatic cancer, enlarged hilar node). Therefore, the indications of intra-ductal RFA remain controversial, and the basic theory of this technique as a palliative treatment in extra-luminal biliary compression should also be further studied. Additionally, previous studies mostly utilized the endoscopic approach with this technique for the treatment of malignant biliary obstruction. Whether the endoscopic approach is better than the percutaneous route warrants further study.

Considering that covered SEMS are associated with increased risk of pancreatitis and cholecystitis but have comparable benefits to uncovered stents, uncovered SEMS placement was performed for all patients in our study. There were no severe complications, such as bile duct perforation, bile leak, or acute pancreatitis. However, we observed atrial fibrillation and sudden onset of chronic heart failure in one patient after the procedure, which might be a relative contraindication for this technique. We do emphasize that the incidence of cholangitis (32\%) was very high in our group and two patients died within 30 days after the RFA procedure, both due to cholangitis and septic shock. Accordingly, we fully support the prophylactic administration of antibiotics before stent placement to lower the risk of cholangitis $[19,20]$. Additionally, in univariable analysis, previously cholangitis was an independent poor prognosis factor for recurrent biliary obstruction (Table 3).

\section{Conclusions}

In conclusion, percutaneous RFA and stent placement is a technically safe and feasible therapeutic option for the palliative treatment of malignant biliary obstruction. We present more of our experiences with the use of this technique for select patients, and demonstrate the feasibility, with a satisfactory safety profile.

\section{Abbreviations \\ ALT: alanine aminotransferase; AST: aspartate aminotransferase; DB: direct bilirubin; DSA: digital subtraction angiography; ERCP: endoscopic retrograde cholangiopancreatography; GGT: gamma-glutamyl transpeptidase; OS: overall survival; PDT: photodynamic therapy; PTC: percutaneous transhepatic cholangiography; RFA: radiofrequency ablation; SEMS: Self-expandable metal stents; TB: total bilirubin}

\section{Acknowledgments}

We would like to thank Ziping Li, Shiting Feng (Department of Radiology, the First Affiliated Hospital, Sun Yat-sen University, Guangzhou) for imaging assistance, and thank Yuantao Hao (School of Public Health, Sun Yat-sen University, Guangzhou) for statistical assistance in the manuscript.

Funding

NO external funding. 


\section{Availability of data and material}

The datasets generated and/or analyzed during the current study are available from the corresponding authors on reasonable request, but no information infringing on the privacy of the participants will be given.

\section{Authors' contributions}

$J \mathrm{~L}$ and $\mathrm{YW}$ designed the research. WC and WF wrote the main manuscript. $\mathrm{ML}, \mathrm{YZ}$ and $\mathrm{WY}$ performed the statistical analysis. JL and WF edited the manuscript. All authors have read and approved the final manuscript.

\section{Competing interests}

The authors declare that they have no competing interests.

\section{Consent for publication}

Not applicable.

\section{Ethics approval and consent to participate}

The study was approved by the Ethics Committee of the First Affiliated Hospital of Sun Yat-sen University and was carried out in accordance with the Declaration of Helsinki, and the requirement for written informed consent was obtained from all participants.

\section{Publisher's Note}

Springer Nature remains neutral with regard to jurisdictional claims in published maps and institutional affiliations.

Received: 29 September 2016 Accepted: 12 April 2017

Published online: 24 April 2017

\section{References}

1. Mensah ET, Martin J, Topazian M. Radiofrequency ablation for biliary malignancies. Curr Opin Gastroenterol. 2016;32(3):238-43.

2. Perdue DG, Freeman ML, DiSario JA, Nelson DB, Fennerty MB, Lee JG, Overby CS, Ryan ME, Bochna GS, Snady HW, et al. Plastic versus selfexpanding metallic stents for malignant hilar biliary obstruction: a prospective multicenter observational cohort study. J Clin Gastroenterol. 2008;42(9):1040-6.

3. Loew BJ, Howell DA, Sanders MK, Desilets DJ, Kortan PP, May GR, Shah RJ, Chen YK, Parsons WG, Hawes RH, et al. Comparative performance of uncoated, self-expanding metal biliary stents of different designs in 2 diameters: final results of an international multicenter, randomized, controlled trial. Gastrointest Endosc. 2009:70(3):445-53.

4. Ballinger $A B, M c H u g h ~ M$, Catnach SM, Alstead EM, Clark ML. Symptom relief and quality of life after stenting for malignant bile duct obstruction. Gut. 1994;35(4):467-70.

5. Kullman E, Frozanpor F, Soderlund C, Linder S, Sandstrom P, LindhoffLarsson A, Toth E, Lindell G, Jonas E, Freedman J, et al. Covered versus uncovered self-expandable nitinol stents in the palliative treatment of malignant distal biliary obstruction: results from a randomized, multicenter study. Gastrointest Endosc. 2010;72(5):915-23.

6. Zhu HD, Guo JH, Zhu GY, He SC, Fang W, Deng G, Qin YL, Li GZ, Coldwell DM, Teng GJ. A novel biliary stent loaded with (125)l seeds in patients with malignant biliary obstruction: preliminary results versus a conventional biliary stent. J Hepatol. 2012;56(5):1104-11.

7. Pai M, Valek V, Tomas A, Doros A, Quaretti P, Golfieri R, Mosconi C, Habib N. Percutaneous Intraductal radiofrequency ablation for clearance of occluded metal stent in malignant biliary obstruction: feasibility and early results. Cardiovasc Inter Radiol. 2014;37(1):235-40.

8. Zoepf T, Jakobs R, Arnold JC, Apel D, Riemann JF. Palliation of nonresectable bile duct cancer: improved survival after photodynamic therapy. Am J Gastroenterol. 2005;100(11):2426-30.

9. Sharaiha RZ, Natov N, Glockenberg KS, Widmer J, Gaidhane M, Kahaleh M. Comparison of metal stenting with radiofrequency ablation versus stenting alone for treating malignant biliary strictures: is there an added benefit? Dig Dis Sci. 2014;59(12):3099-02.

10. Itoi T, Isayama H, Sofuni A, Itokawa F, Tamura M, Watanabe Y, Moriyasu F, Kahaleh M, Habib N, Nagao T, et al. Evaluation of effects of a novel endoscopically applied radiofrequency ablation biliary catheter using an exvivo pig liver. J Hepato-Bil-Pan Sci. 2012;19(5):543-7.
11. Khorsandi SE, Zacharoulis D, Vavra P, Navarra G, Kysela P, Habib N. The modern use of radiofrequency energy in surgery, endoscopy and interventional radiology. Eur Surg. 2008;40(5):204-10.

12. Steel AW, Postgate AJ, Khorsandi S, Nicholls J, Jiao L, Vlavianos P, Habib N, Westaby D. Endoscopically applied radiofrequency ablation appears to be safe in the treatment of malignant biliary obstruction. Gastrointest Endosc. 2011;73(1):149-53.

13. Monga A, Gupta R, Ramchandani M, Rao GV, Santosh D, Reddy DN. Endoscopic radiofrequency ablation of cholangiocarcinoma: new palliative treatment modality (with videos). Gastrointest Endosc. 2011;74(4):935-7.

14. Liberato MJ, Canena JM. Endoscopic stenting for hilar cholangiocarcinoma: efficacy of unilateral and bilateral placement of plastic and metal stents in a retrospective review of 480 patients. BMC Gastroenterol. 2012;12:103.

15. Figueroa-Barojas P, Bakhru MR, Habib NA, Ellen K, Millman J, Jamal-Kabani A Gaidhane M, Kahaleh M. Safety and efficacy of radiofrequency ablation in the Management of Unresectable Bile Duct and Pancreatic Cancer: a novel palliation technique. J of Oncology. 2013;2013:1-5.

16. Mizandari M, Pai M, Xi F, Valek V, Tomas A, Quaretti P, Golfieri R, Mosconi C, Guokun A, Kyriakides C, et al. Percutaneous Intraductal radiofrequency ablation is a safe treatment for malignant biliary obstruction: feasibility and early results. Cardiovasc Inter Radiol. 2013;36(3):814-9.

17. Wadsworth CA, Westaby D, Khan SA. Endoscopic radiofrequency ablation for cholangiocarcinoma. Curr Opin Gastroen. 2013;29(3):305-11.

18. Tal AO. Intraductal endoscopic radiofrequency ablation for the treatment of hilar non-resectable malignant bile duct obstruction. World J Gastroint Endosc. 2014;6(1):13.

19. Li TF, Huang GH, Li Z, Hao CF, Ren JZ, Duan XH, Zhang K, Chen C, Han XW, Jiao DC, et al. Percutaneous transhepatic cholangiography and intraductal radiofrequency ablation combined with biliary stent placement for malignant biliary obstruction. J Vasc Interv Radiol. 2015;26(5):715-21.

20. Kallis Y, Phillips N, Steel A, Kaltsidis H, Vlavianos P, Habib N, Westaby D. Analysis of endoscopic radiofrequency ablation of biliary malignant strictures in pancreatic cancer suggests potential survival benefit. Dig Dis Sci. 2015;60(11):3449-55.

21. Wang Y, Cui W, Fan W, Zhang Y, Yao W, Huang K, Li J: Percutaneous intraductal radiofrequency ablation in the management of unresectable Bismuth types III and IV hilar cholangiocarcinoma. Oncotarget. 2016,16;7(33): 53911-20.

22. Oken MM, Creech RH, Tormey DC, Horton J, Davis TE, McFadden ET, Carbone PP. Toxicity and response criteria of the eastern cooperative Oncology group. Am J Clin Oncol. 1982;5(6):649-55.

23. De Palma GD, Pezzullo A, Rega M, Persico M, Patrone F, Mastantuono L, Persico G. Unilateral placement of metallic stents for malignant hilar obstruction: a prospective study. Gastrointest Endosc. 2003;58(1):50-3.

24. Paik WH, Park YS, Hwang JH, Lee SH, Yoon CJ, Kang SG, Lee JK, Ryu JK, Kim YT, Yoon YB. Palliative treatment with self-expandable metallic stents in patients with advanced type III or IV hilar cholangiocarcinoma: a percutaneous versus endoscopic approach. Gastrointest Endosc. 2009;69(1): $55-62$.

25. Strand DS, Cosgrove ND, Patrie JT, Cox DG, Bauer TW, Adams RB, Mann JA, Sauer BG, Shami VM, Wang AY. ERCP-directed radiofrequency ablation and photodynamic therapy are associated with comparable survival in the treatment of unresectable cholangiocarcinoma. Gastrointest Endosc. 2014; 80(5):794-804.

26. Isayama H, Hamada T, Yasuda I, Itoi T, Ryozawa S, Nakai Y, Kogure H, Koike K. TOKYO criteria 2014 for transpapillary biliary stenting. Dig Endosc. 2015; 27(2):259-64

27. Ortner MA. Photodynamic therapy for cholangiocarcinoma: overview and new developments. Curr Opin Gastroenterol. 2009;25(5):472-6.

28. Wu T, Li H, Li W, Ao G, Lin H, Zheng F, Song J. Percutaneous intraluminal radiofrequency ablation for malignant extrahepatic biliary obstruction: a safe and feasible method. Dig Dis Sci. 2015;60(7):2158-63.

29. Dolak W, Schreiber F, Schwaighofer H, Gschwantler M, Plieschnegger W, Ziachehabi A, Mayer A, Kramer L, Kopecky A, Schrutka-Kolbl C, et al. Endoscopic radiofrequency ablation for malignant biliary obstruction: a nationwide retrospective study of 84 consecutive applications. Surg Endosc. 2014;28(3):854-60. 